Haya: The Saudi Journal of Life Sciences

Abbreviated Key Title: Haya Saudi J Life Sci

ISSN 2415-623X (Print) |ISSN 2415-6221 (Online)

Scholars Middle East Publishers, Dubai, United Arab Emirates

Journal homepage: https://saudijournals.com

Original Research Article

\title{
An Initiative for Developing Low Cost Hydroponic System
}

\author{
Sabrina Naz ${ }^{1 *}$, A. H. M. Rezaul Haq ${ }^{2}$, Md. Mizanur Rahman ${ }^{3}$ and Masuma Khatun
}

Department of Botany, University of Rajshahi, Rajshahi 6205 Bangladesh

DOI: $10.36348 /$ sjls.2021.v06i01.003 $\quad$ | Received: 01.10 .2020 | Accepted: 13.10 .2020 | Published: 28.01 .2021

*Corresponding author: Sabrina Naz

Abstract

The paper deals to minimize the water crisis of a drought prone area in Bangladesh. In this research an alternative and low-cost effective cultivation method has been developed. In the technique a composition of traditional agricultural fertilizers (Agronaris, DAP, MP, Dolochun, Gypsum, Magnesium Sulfate and Iron Sulfate), cow urine and pond water has been used as nutrient medium. For medium of cultivation recyclable bottles, foams, bamboo, coco coir, semidried Eichhornia leaves were used. Tomato (Lycopersicon esculentum Mill.); Pepper (Capsicum); Lettuce (Lactuca sativa) were used as experimental plant. Plant survival rate of tomato showed highest value of $92.86 \%$ respectively followed by lettuce with $78.57 \%$ and pepper with $42.86 \%$ in value after 2 months of observation. Growth rate and hairy root formation were found to be higher in tomato than lettuce and pepper. Pepper showed less response in these three parameters where maturation rate of pepper is better than Tomato as pepper needs $39.33 \pm 0.49$ days to ripen the fruits but tomato took $47.5 \pm 0.39$ days in fruit ripening. Though tomato takes more time to be mature than pepper, the growth of the both plants are as same.

Keywords: Lowcost, Hydroponic System, Drought prone, Bangladesh.

Copyright (C) 2021 The Author(s): This is an open-access article distributed under the terms of the Creative Commons Attribution 4.0 International License (CC BY-NC 4.0) which permits unrestricted use, distribution, and reproduction in any medium for non-commercial use provided the original author and source are credited.

\section{INTRODUCTION}

Hydroponics is the soilless agricultural technology in nutrient solutions (water and fertilizers) that contain all the essential elements needed by a plant for its normal growth and development with using of an inert medium, such as gravel, sand, peat, vermiculite, pumice, perlite, coco coir, sawdust, rice hulls to provide mechanical support in a controlled environment [1]. Hydroponics is the alternative of conventional agriculture to produce vegetables, flowers or crops in drought area, water scare area, fallow lands, toxic metals contaminated lands etc. The technique provide many advantages: prevent plants from soil-borne diseases, pests and weeds [2]; uniform and stable use of water and nutrients (fertilizers) that are reusable [3]; higher maturity rate with eco-friendly such as omitted herbicides, weedicides and pesticides [4]; higher yielding and food production rate throughout the year [5]; reduce labour and eliminate several traditional agricultural practices, such as cultivating, weeding, watering, and tilling [6].

Bangladesh is an over populated developing country. Though the food demands increase, rapid industrialization and urbanization cause the great destruction to the environments and its components i.e. soil, water, air to compete the food demanding challenges. Food production has become a great concern as millions of hectares become unusable because of soil degradation, soil borne diseases, poor physical properties, conventional agricultural practices e.g. pesticides usages and apparently in runoff water, uncontrolled irrigation, excessive usage of chemical fertilizers and other obstacles (i.e. water, climate and energy) [7]. Natural calamities such as flood, drought, high tide, erosion etc. also create the crisis of food production all around the country. Barind tract the northern part of the country is the most drought prone area [8] which responsible for arid land and remain uncultivated for the highest portion of time in a year.

Soilless cultivation technique has been adapted by Bangladeshi people mainly at southern and coastal region where wetlands are available and waterlogged condition sustains for almost throughout the year. Therefore, local peoples developed cost effective sustainable soilless floating bed agriculture technique locally known as Dhap, Geto, Baira etc. [9]. In northern region especially Barind tract has not yet developed any soilless technique due to high initial set up cost [10], highest management skills requirement [1] which are disadvantages of traditional hydroponics technique. Therefore, resilience of the climate change threat 
through adaptation and innovation of hydroponic system in drought prone area of Bangladesh can be achieved. A new farmer friendly hydroponics system has been adopted in present study to minimize the water scarcity, the production cost and the toxic impacts on vegetables.

\section{MATERIALS AND METHODS}

\section{Plant Samples and Experimental Field Preparation}

Three highly consumed vegetables, Tomato, Pepper and Lettuce has been selected for the experiment. The seedlings have been prepared through seed sowing in room condition and transferred the seedlings in net house of 1100 sq. ft. with proper ventilation and natural daylight excess.

\section{Nutrient Medium}

Agricultural fertilizers showed in Table-1 has been used to abate the cost for the installation of hydroponics techniques and to reduce direct contamination of inorganic chemicals. To prepare a working nutrient medium $125 \mathrm{~g}$ of stock mixture were used to $20 \mathrm{~L}$ of pond water and $625 \mathrm{ml}$ raw cow urine were added as source of organic nitrogen in the solution and gently mixed up the solvents with the fertilizers and adjusted $\mathrm{pH}$ in 5-7 and electric conductivity (EC) in 1-3 $\mu \mathrm{S}$ by adding extra water if required. Then the hydroponic solution was being aerated with aeration pump for 48 hours to remove the microbial contamination.

\section{Preparation for Transplantation: plant holder and hydroponic containers}

As hydroponics is mainly a soil less plant development technique, it is necessary to ensure a suitable hard component that used as substrate. To ensure substrate bamboo and plastic bottles were being used; these were made useable (carrying hydroponics solution) filled with coco coir and transplanted the plants using foam to stable the plant roots and uptake the nutrition. Expanded soil and Eicchornia leaves were also being used as humus in the medium to resist the drought condition and to provide support for the plants. Hydroponic solution was continuously supplied through saline pipe from a container during the daytime.

\section{REULTS AND DISCUSSIONS}

Hydroponics technique is also an expensive one therefore the study has been undertaken to observe the effect of low costing materials used as build up hydroponics technique of the mentioned plants. Many researches in hydroponics technique has been conducted regarding lettuce and tomato where the production showed much higher in per acre than agriculture fields [11]. Therefore, lettuce, tomato and pepper had been used as experimental plants as the plants also have great commercial value in Bangladesh. Studied plants are mainly winter vegetables. Thus, all the parameters have been observed from November to January as the experiment conducted in that time. Plants survival rate and adaptability was the first and foremost steps to establish the new low-cost hydroponic techniques and further study conducted through observation of plants developmental growth in different parameters.

\section{Adaptability of the plants}

For the primary growth observation adaptability of the plants is of great importance as it helps to find out the rate of further success of the modified Hydroponics Techniques. Hydroponics is mainly soilless plant growing technique so there is almost zero possibility of contamination through soil borne pathogens. So, survival rate only depends mainly on the availability of nutrients from the solution as well as on fungal and bacterial infection rate. In the present study only availability of the nutrients considered as survival parameter and following result has been observed.

The plant survival rate in $4^{\text {th }}$ and $8^{\text {th }}$ weeks were observed and depicted in Figure: 1. Tomato seedlings showed great response in hydroponics solution and in experimental environment including the hydroponics system. As the percentage of survived tomato plant is $92.86 \%$ after a month which remain same after 2 months. Where Pepper showed less adaptability rate after 2 months. Pepper's survival rate was observed $78.57 \%$ in $1^{\text {st }}$ month which decrease in $2^{\text {nd }}$ month and fall down to $42.86 \%$ that indicates environmental condition and supply of hydroponics solution was not adequate for the Pepper to develop. On the other hand, lettuce seedling also showed great response as its survival rate was $85.71 \%$ in $1^{\text {st }}$ month though the rate was decreased in $2^{\text {nd }}$ month and fall on $78.57 \%$.

As the fungal and bacterial infection on the plants showed no significant effect on their survival so the differences on rates are mainly due to solution supply and transplantation process in the experiment. Whereas, Pepper showed a lesser number of adaptabilities with the new environmental condition. But Tomato and Lettuce are showed great response in the new environmental condition showed in Figure:2. The method considered most efficient for Tomato as the plant showed $43 \%$ survived plant among these three experimental plants.

\section{Hairy root formation}

All hydroponic cultures rely on a nutrient solution to deliver essential elements to the plant. In addition to the nutrients, the roots also need a steady supply of oxygen. When roots become anoxic, they are unable to take up and transport metabolites to the rest of the plant body [12]. In this experiment plants grown on inert media and nutrient was supplied from the hydroponics solution by dripping solution in wet-dry cycle. Therefore, roots were enlarged in length and form hairy root system which is necessary for plants to 
absorb high amount of nutrients. In hydroponics system hairy root developed is must for wet and dry cycle in the cycle it is necessary for the transplanted plants to uptake nutrients from the solution remain at the lower part of the holder as well as from absorbed coir and Eicchornia leaves. Hence hairy root formation and development is must for the development and to increase the productivity of the plants.

In this experiment, $4^{\text {th }}$ week was considered as a developed condition for the experimental plants therefore hairy root observation showed only for the $1^{\text {st }}$ month after cultivation. Here in Table:1, "+" shows the increase rate of hairy root in which " +++ " indicates the most developed hairy roots among all of them and "++" show second most development of hairy roots.

Response to the modified hydroponics solution and environment condition in development of hairy root, tomato seedling was superior. Pepper showed less response to the hairy root formation than Tomato and Lettuce.

\section{Growth and Development rate of the plants}

Growth and development rate are determined with the increasing length of the plants. As the growth and development rate is proportional with nutrient availability. Adequate nutrients solution helps the plant to grow faster and not to show any symptoms that could be obstacle. Plants productivity depends much on the success of growth and development of the plants so plant growth rate is one of the main parameters to find out the success of the experiment.

From the Table: 2 individual growth rate of tomato varies from $20.6 \mathrm{~cm}$ to $19 \mathrm{~cm}$ which got the mean value of $20.38 \mathrm{~cm}$ with 0.39 as standard error value at the initiated stage. The mean value got arise to $43.1 \mathrm{~cm}$ after a month which showed its increase rate more than double in value and continue its growth rate for the next month as it showed average length value is including standard error is $(62.13 \pm .47) \mathrm{cm}$. The mean length of Pepper plant also tabulated in table-2, which is not as promising as tomato. Pepper seedling was about around $12-13 \mathrm{~cm}$ which got 22 to 23.5 except one which got the highest length of $24.6 \mathrm{~cm}$. average length of Pepper was (23.02 $\pm .0 .33) \mathrm{cm}$. Pepper showed nearly the same growth rate at $2^{\text {nd }}$ month. The average length of the $2^{\text {nd }}$ month was $(35.92 \pm .29) \mathrm{cm}$ which was almost thrice of the initial length of the plant.

In terms of lettuce great response rate observed as it enlarged in length nearly three times from the initial stages in $1^{\text {st }}$ month and above four times in $2^{\text {nd }}$ month. In first month length varied from $12.5 \mathrm{~cm}$ to $13.8 \mathrm{~cm}$ where average value was $(13.03 \pm 0.16) \mathrm{cm}$. which increased to $(21.9 \pm 0.28)$ in $2^{\text {nd }}$ month. The result indicates lettuce response rate is much higher than tomato and pepper in the improved hydroponics medium as tomato showed enlargement length in above the double value from the initial stage and pepper showed only nearly double value.

\section{Observation of maturity stage}

Maturity stage was observed on tomato and pepper. Their flower initiation, fruit development and fruit ripening were considered as their mature stage development in days. Iron sulfate (containing EC value of $0.5 \mu \mathrm{S}$ ) had been used as spray to initiate the flowering of the plants. The spray was used before the sun rise in per day a week.

Table:3 showing the results of tomato and Pepper maturation rate. It takes $(14.83 \pm 0.88)$ and $(17.67 \pm 0.49)$ days respectively to initiate the flower after cultivation. But the fruit setting time took only 12 days after the flower formation as it takes $(26 \pm 0.34)$ days from the beginning and fruit maturation took around 11 days as the average value was $(47.5 \pm 0.39)$ days for tomato. Normally in soil-based cultivation tomato plant take 45 to 100 days for maturation that indicates the fruit maturation of tomato showed natural response to this modified solution. On the other hand, Pepper's flower formation took 3 days more than tomato's flower formation though fruit set took only 8 days from the flower formation and $(25.67 \pm 0.84)$ days as same as tomato's result. Fruit maturation also took a smaller number of days from result of tomato as the days value was $(39.33 \pm 0.49)$ days.

Despite of having lowest adaptability ability, lowest rate of hairy root formation and lowest growth rate, pepper showed great maturation ability in this current condition. 


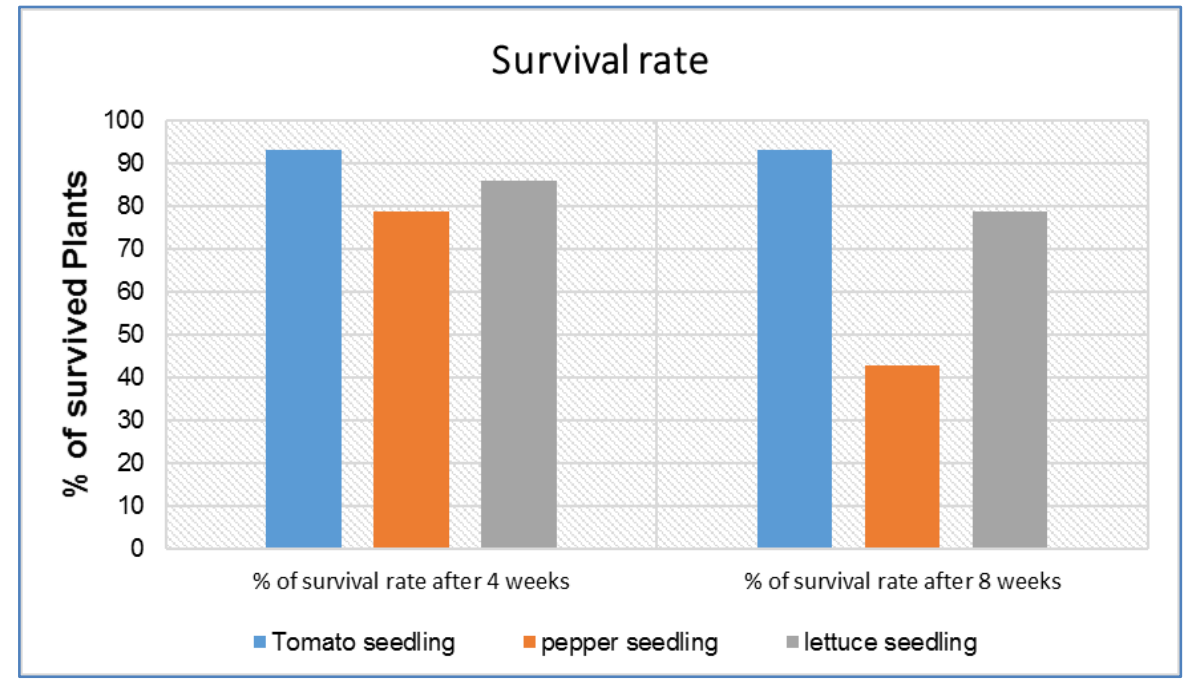

Fig-1: Graphical distribution Plant survival rate

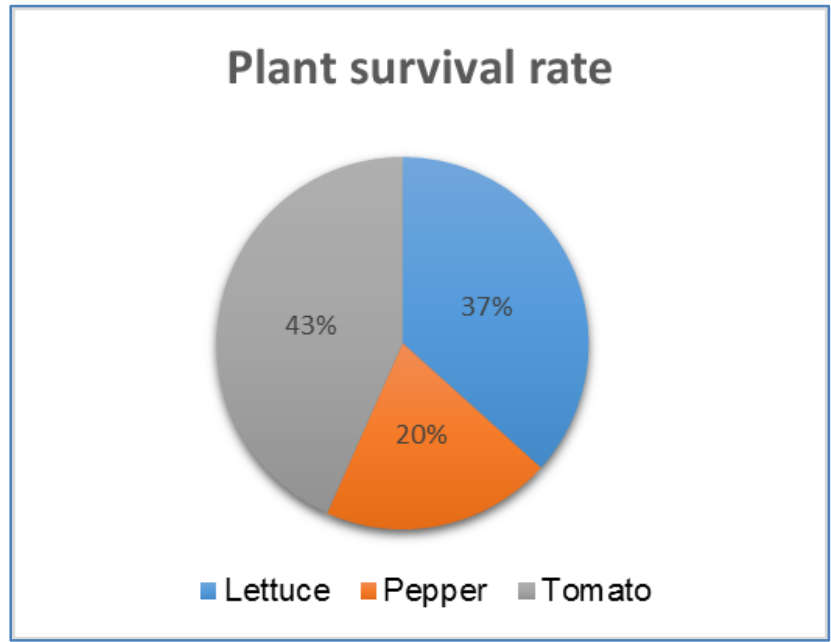

Fig-2: Graphical distribution Plant survival rate

Table-1: Inorganic Composition of the Nutrient Solution

\begin{tabular}{|l|l|}
\hline Inorganic components & $\mathbf{2 . 7}$ kg Stock Mixture \\
\hline Agronourish & $1000 \mathrm{~g}$ \\
\hline DAP (Diammonium phosphate) & $550 \mathrm{~g}$ \\
\hline Muriate of Potash (Potasium chloride) & $400 \mathrm{~g}$ \\
\hline Dolochun (Calcium Oxide) & $400 \mathrm{~g}$ \\
\hline Gypsum (Calcium Sulfate dihydrate) & $200 \mathrm{~g}$ \\
\hline Magnesium Sulfate & $200 \mathrm{~g}$ \\
\hline
\end{tabular}

Table-2: Developmental stages of hairy root

\begin{tabular}{|l|l|}
\hline Experimental unit & Observation of 4th week \\
\hline Tomato seedling & +++ \\
\hline Pepper seedling & + \\
\hline Lettuce seedling & ++ \\
\hline
\end{tabular}

Table-3: Plant length of Tomato, Pepper and Lettuce in different time stage

\begin{tabular}{|l|l|l|l|}
\hline Samples & Length at Initial Stage (cm.) & Length after 4 weeks $(\mathbf{c m})$. & $\begin{array}{l}\text { Length after } \\
\text { 8 weeks }(\mathbf{c m} .)\end{array}$ \\
\hline Tomato & $20.38 \pm 0.39$ & $43.1 \pm 0.28$ & $62.13 \pm 0.47$ \\
\hline Pepper & $12.6 \pm 0.12$ & $23.02 \pm 0.33$ & $35.92 \pm 0.29$ \\
\hline Lettuce & $5.72 \pm 0.11$ & $13.03 \pm 0.17$ & $21.9 \pm 0.28$ \\
\hline
\end{tabular}


Table-4: Analysis to observed maturity on Tomato and Pepper

\begin{tabular}{|l|l|l|l|}
\hline Plant samples & Flower initiation day & Fruit initiation day & Fruit maturity in days \\
\hline Tomato & $14.83 \pm 0.88$ & $26 \pm 0.34$ & $47.5 \pm 0.39$ \\
\hline Pepper & $17.67 \pm 0.49$ & $25.67 \pm 0.84$ & $39.33 \pm 0.49$ \\
\hline
\end{tabular}

\section{CONCLUSION}

Present study was undertaken to minimize the water crisis in drought prone Barind area. As in traditional agriculture supply of mass quantity of water is needed for irrigation process where farmers find problem as Barind area is mainly a drought prone area. Therefore, hydroponics technique has been applied as less quantity of water is need in this technique. As hydroponics technique is expensive to bear by a farmer, living below poverty line, so an improved hydroponics technique has been applied in some commonly grown vegetables: Tomato, Pepper and Lettuce in our country have high commercial value. In this technique there were no significant changes in growth pattern of the plants as it took the same time duration as traditional agriculture method to complete to their life cycles. Pond water has been used in this technique which is available in Barind area and can easily be collected therefore farmers can easily ensure the water supply for the solution need for hydroponics technique. Farmers need not to bear high amount of money to buy hydroponics equipment but in the present study it has been established using plastic bottles, foams, bamboo, coco coir, semi dried Eicchornia leaves as substrate is a success and traditionally used fertilizers in conventional method used as components in the nutrient medium provided successful growth and production cycle of the selected three plant specimens. It is also to be mentioned all the components are much cheaper than the Hydroponics equipment and its establishment cost is much cheaper than that of Hydroponics system. All the components used in this study are also in the easy reach of the farmers.

\section{REFERENCES}

1. Jensen, M. H. (1997). Hydroponics. Hort. Science, 32(6), 1018-1021.

2. Munoz, H. (2005). Hydroponic home-based vegetable production system manual (No. IICAF01 54). IICA, Georgetown (Guyana). 22.

3. Lommen, Willemien, J.M. (2007). "The canon of potato science: 27. Hydroponics." Potato Research, 50;3-4: 315.

4. Resh, H. M. (2012). Hydroponic food production: a definitive guidebook for the advanced home gardener and the commercial hydroponic grower. CRC Press. Taylor and Francis Group; 513.

5. Barbosa, G. L., Gadelha, F. D. A., Kublik, N., Proctor, A., Reichelm, L., Weissinger, E., \& Halden, R. U. (2015). Comparison of land, water, and energy requirements of lettuce grown using hydroponic vs. conventional agricultural methods. International journal of environmental research and public health, 12(6), 6879-6891.

6. Jovicich, E., Cantliffe, D. J., \& Stoffella, P. J. (2002, March). " Spanish" pepper trellis system and high plant density can increase fruit yield, fruit quality, and reduce labor in a hydroponic, passiveventilated greenhouse. In VI International Symposium on Protected Cultivation in Mild Winter Climate: Product and Process Innovation 614 (pp. 255-262).

7. BeVier, G. (2012). Global food systems: feeding the world. Reproduction in Domestic Animals, 47(4), 77-79.

8. Shahid, S., \& Behrawan, H. (2008). Drought risk assessment in the western part of Bangladesh. Natural hazards, 46(3), 391-413.

9. HAQ, A. (2009). Some thoughts on soilless agriculture in Bangladesh. Bangladesh: Wetland Resource Development Society.

10. Domingues, D. S., Takahashi, H. W., Camara, C. A., \& Nixdorf, S. L. (2012). Automated system developed to control $\mathrm{pH}$ and concentration of nutrient solution evaluated in hydroponic lettuce production. Computers and electronics in agriculture, 84, 53-61.

11. Singh, S., \& Singh, B. S. (2012, May). Hydroponics-A technique for cultivation of vegetables and medicinal plants\|. In Proceedings of 4th Global conference on Horticulture for Food, Nutrition and Livelihood Options. Bhubaneshwar, Odisha, India (p. 220).

12. Gibbs, J., Turner, D. W., Armstrong, W., Darwent, M. J., \& Greenway, H. (1998). Response to oxygen deficiency in primary maize roots. I. Development of oxygen deficiency in the stele reduces radial solute transport to the xylem. Functional Plant Biology, 25(6), 745-758. 